\title{
ВИКОРИСТАННЯ РІВНЯНЬ ЛАГРАНЖА ДРУГОГО РОДУ ДЛЯ ОТРИМАННЯ СТАТИЧНОЇ ХАРАКТЕРИСТИКИ ВІДЦЕНТРОВОГО РЕГУЛЯТОРА
}

\author{
М.О. Шихайлов, В.М. Головко, проф., д-р техн. наук, В.П. Коханєвич, канд. техн. наук \\ Інститут відновлюваної енергетики НАН України, \\ 02094, вул. Гната Хоткевича, 20А, м. Київ, Україна
}

Вітроустановки малої потужності мають високе значення величини кутової швидкості обертання ротора. Крім того, під час їх експлуатації необхідно враховувати випадковість характеру вітрового потоку та зміни його величини в широких межах. 3 огляду на ие вітроустановки малої потужності, особливо вітроелектричні (ВЕУ), повинні бути обладнані системами регулювання кутової швидкості обертання ротора. Зважсаючи на те, щзо основними власниками ВЕУ є приватні особи з обмеженими територіальними ресурсами, ВЕУ здебільшого розміщуються в безпосередній близькості до будівель. Тому серед багатьох вимог до ВЕУ на перший план, крім простоти ї̈ конструкції та невеликої вартості, виходить безпека експлуатації. Серед великої кількості систем регулювання вітроустановок малої потужності найбільшою мірою цим вимогам відповідають системи з використанням відцентрових регуляторів різноманітних конструкцій. Відомі засоби їх розрахунку вимагають вибір відповідної загальної теореми динаміки. Для систем з декількома ступенями свободи вирімення задач значно ускладнюється, тому, що при иььму вимагається сумісне застосування деяких загальних теорем та інших співвідношень динаміки, вибір яких інколи викликає значні труднощі. Для конструювання нових систем регулювання інженерам-конструкторам необхідні спрощені методи розрахунку параметрів регулятора, щуоб визначитись з основними масогабаритними показниками майбутньої конструкиії. В даній роботі запропонована система диферениійних рівнянь руху елементів відиентрового регулятора оригінальної конструкиії з використанням рівнянь Лагранжа другого роду. Рішення цієі системи рівнянь при усталеному режимі дозволило отримати вирази для визначення параметрів регулятора для забезпечення номінальних обертів ротора та вибрати жорсткість пружини для забезпечення необхідного діапазону відхилень обертів ротора від номінального значення в заданому діапазоні кутів регулювання. Ці вирази можуть бути використані для подібних за своєю конструкиією відиентрових регуляторів роторів вітроустановок. Бібл. 8, рис. 5 .

Ключові слова: вітроустановка, диференційні рівняння руху вітроустановки, відцентровий регулятор кутової швидкості.

\section{USE OF LOGRANGE EQUATIONS OF THE SECOND GENERAL FOR OBTAINING STATIC CHARACTERISTICS OF THE CENTRIFUGAL REGULATION}

M. Shykhailov, V. Golovko, prof., dr. tech. sciences, V. Kokhanevich, cand. of tech. sciences.

Institute of Renewable Energy of the National Academy of Sciences of Ukraine,

02094, 20A Hnata Khotkevycha St., Kyiv, Ukraine

Low power wind turbines have a high value of the angular velocity of the rotor. In addition, it is also necessary to take into account the randomness of the nature of the wind flow and changes in its magnitude in a wide range. All these features require that low-power wind turbines, especially wind-driven wind turbines, be equipped with rotor angular speed control systems. Due to the fact that the main owners of wind turbines are individuals with limited territorial resources, wind turbines are mostly located in close proximity to buildings. Thus, among the many requirements for wind turbines, safety in operation comes to the fore, in addition to simplicity and low cost. Among the large number of control systems for low-power wind turbines, systems using centrifugal regulators of various designs meet these requirements to the greatest extent. Known means of their calculation require the choice of the appropriate general theorem of dynamics. In the case of systems with several degrees of freedom, the solution of problems is much more complicated, (C) М.О. Шихайлов, В.М. Головко, В.П. Коханєвич, 2021 
because it requires the combined application of some general theorems and other relations of dynamics, the choice of which sometimes causes considerable difficulties. When designing new control systems, design engineers need simplified methods for calculating the parameters of the regulator to determine the main mass and size indicators of the future design. In this paper we propose a system of differential equations of motion of the elements of the centrifugal regulator of the original design using Lagrange equations of the second kind. The solution of this system of equations at steady state allowed to obtain expressions for determining the parameters of the controller to ensure the nominal rotor speed and select the spring stiffness to ensure the required range of deviations of the rotor speed from the nominal value in a given range of control angles. These expressions can be used for similar in design centrifugal regulators of wind turbine rotors. Ref. 8, fig. 5 .

Keywords: wind turbine, differential equations of wind turbine motion, centrifugal angular velocity regulator.

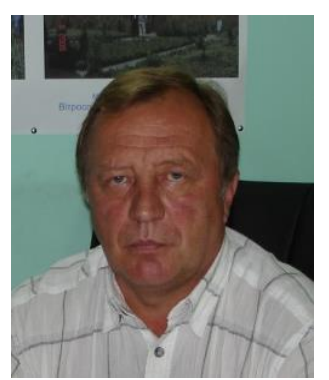

М.О. Шихайлов M. Shykhailov

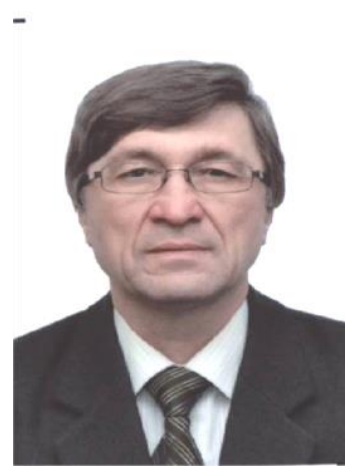

В.М. Головко V. Golovko

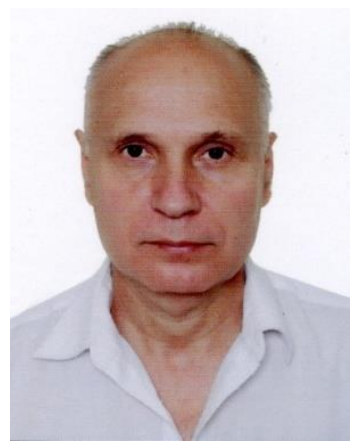

В.П. Коханєвич V. Kokhanievych
Відомості про автора: науковий співробітник Інституту відновлюваної енергетики НАН України

Освіта: Київський політехнічний інститут.

Спеціальність «Гідропневмоавтоматика та гідропривод»

Наукова сфера: вітроенергетика, вітроустановки малої потужності, системи управління

Публікації: 222

ORCID: 0000-0003-1845-9904

Контакти: тел./факс: +38(044)206-28-09

e-mail: renewable@ukr.net

Відомості про автора: провідний науковий співробітник Інституту відновлюваної енергетики НАН України

Освіта: Українська сільськогосподарська академія. Спеціальність «Електрифікація сільського господарства»

Наукова сфера: відновлювані джерела енергії, вітроенергетика, вітроустановки малої потужності, автономні системи енергозабезпечення

Публікації: 168

ORCID: 0000-0003-0195-9654

Контакти: тел./факс: +38(044)206-28-09

e-mail: renewable@ukr.net

Відомості про автора: старший науковий співробітник Інституту відновлюваної енергетики НАН України

Освіта: Київський політехнічний інститут. Спеціальність «Технологія машинобудування, металорізальні верстати та інструменти»

Наукова сфера: вітроенергетика, вітроустановки малої потужності, системи регулювання та захисту

Публікації: 147

ORCID: 0000-0003-0033-1355

Контакти: тел./факс: +38-044-206-28-09

e-mail: renewable@ukr.net
Author information: researcher in at Institute for Renewable Energy, National Academy of Sciences of Ukraine

Education: Kyiv Polytechnic Institute Specialty «Hydropneumatic automation and hydraulic drive»»

Research area: wind power systems, small capacity wind units, control systems

Publications: 222

ORCID: 0000-0003-1845-9904

Contacts: phone/fax: $+38(044) 206-28-09$

e-mail: renewable@ukr.net

Author information: chief researcher at Institute for Renewable Energy, National Academy of Sciences of Ukraine.

Education: Ukrainian Agricultural Academy. Specialty «Electrification of agriculture»

Research area: renewable sources of energy, wind power systems, small capacity wind units, autonomous power systems

Publications: 168

ORCID: 0000-0003-0195-9654

Contacts: phone/fax: +38(044)206-28-09

e-mail: renewable@ukr.net

Author information: senior researcher at Institute for Renewable Energy, National Academy of Sciences of Ukraine

Education: Kyiv Polytechnic Institute Specialty «Technology of mechanical engineering, metal cutting machines and tools»

Research area: wind energy, low power wind turbines, control and protection systems.

Publications: 147

ORCID: 0000-0003-0033-1355

Contacts: phone/fax: +38(044)206-28-09

e-mail: renewable@ukr.net

Перелік використаних позначень та скорочень:

ВЕУ - вітроелектрична установка;

$v$ - швидкість повітряного потоку;

$R$ - радіус барабану лучкового механізму;

$\omega$ - кутова швидкість обертання ротора;

$P$ - вага кожного з тягарців;

$J_{p}$ - момент інерції ротора; $c$ - жорсткість пружини;

$\theta$ - кут повороту валу, де закріплений регулятор;

$x$-зміщення тягарців у напрямних відносно осі обертання регулятора;

$\varphi$ - кут встановлення лопаті;

$\alpha$ - кут атаки на елементі лопаті. 
Вступ. Відомо, що вітроустановки малої потужності мають високе значення величини кутової швидкості обертання ротора. Крім того, під час їх експлуатації необхідно враховувати випадковість характеру вітрового потоку та зміни його величини в широких межах. 3 огляду на це вітроустановки малої потужності, особливо вітроелектричні (ВЕУ), повинні бути обладнані системами регулювання кутової швидкості обертання ротора. Зважаючи на те, що основними власниками ВЕУ є приватні особи з обмеженими територіальними ресурсами, ВЕУ здебільшого розміщуються в безпосередній близькості до будівель. Тому серед багатьох вимог до ВЕУ на перший план, крім простоти іiі конструкції та невеликої вартості, виходить безпека експлуатації. Серед великої кількості систем регулювання вітроустановок малої потужності найбільшою мірою цим вимогам відповідають системи 3 використанням відцентрових регуляторів різноманітних конструкцій.

У роботі [1] запропонована нова конструкція відцентрового регулятора для вітроустановок, яка на відміну від класичних відцентрових регуляторів, дозволяє його встановлення не тільки в маточині ротора, а й за їі межами. Це приводить до зменшення навантажень на елементи конструкції маточини i, відповідно, підвищує надійність роботи вітроустановки. Для практичного використання даного регулятора інженерам-конструкторам необхідні кінцеві вирази для визначення параметрів як самого регулятора, так і параметрів майбутньої конструкції установки. Відомі засоби розрахунку відцентрових регуляторів вимагають вибір відповідної загальної теореми динаміки. Для систем 3 декількома ступенями свободи розв'язання задач значно ускладнюється, оскільки при цьому вимагається сумісне застосування деяких загальних теорем динаміки, вибір яких інколи викликає значні труднощі. У подібних випадках застосування рівнянь Лагранжа другого роду забезпечує найбільш ефективне рішення задачі та $є$ універсальним методом складання систем диференційних рівнянь руху систем матеріальних точок.

$\mathrm{y}$ роботах [2, 3] наведені способи розрахунку відцентрових регуляторів класичної кінематичної схеми, а саме конічних та плоских, у працях $[4,5]$ - способи розрахунку регулятора, що запропонований Г.Х. Сабініним, 3 розміщенням відцентрових тягарців на махах лопаті. Аналогічні розрахунки потрібно провести і для регулятора, що описаний в [1], для подальшої його практичної реалізації.

Постановка завдання. Метою роботи є розроблення методичних засад розрахунку параметрів відцентрового регулятора для вітроустановки 3 використанням рівнянь Лагранжа другого роду.

Результати досліджень. На рис. 1 зображена розрахункова схема відцентрового регулятора, де вісь 0Х збігається 3 напрямком руху відцентрових тягарців, а вісь 0Y збігається 3 віссю обертання ротора і самого регулятора. Як узагальнені координати прийняті: кут повороту $\theta$ ротора $з$ регулятором навколо осі 0Y та зміщення $x$ тягарця $\boldsymbol{M}$ вздовж осі 0X. 


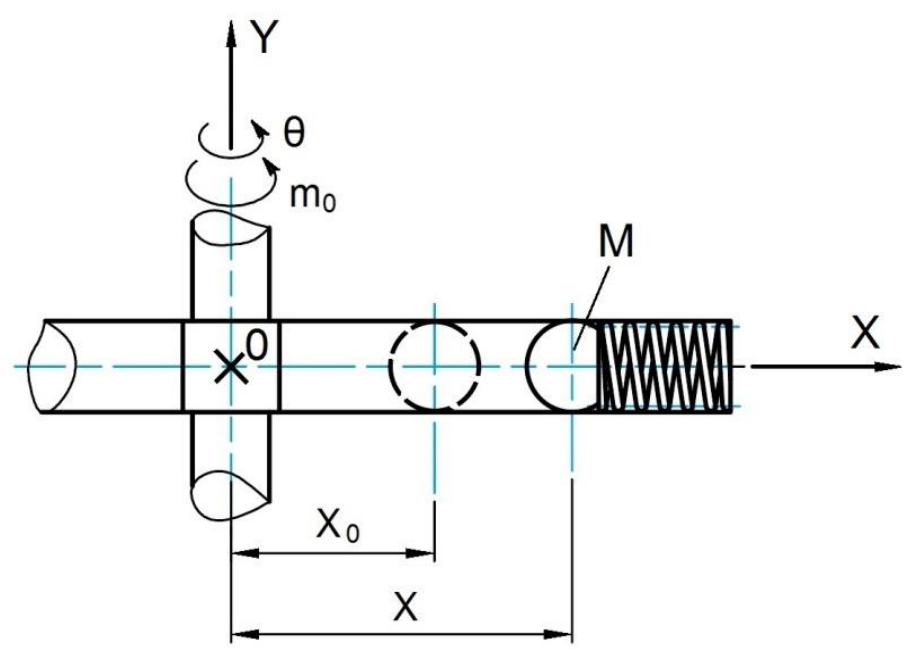

Рис.1 Розрахункова схема відцентрового регулятора 3 тягарцями у напрямних

Fig.1 Calculation scheme of the centrifugal regulator with weights in the guides

Запишемо рівняння Лагранжа для узагальнених координат $\theta$ та $x$ :

$$
\begin{aligned}
& \frac{d}{d t} \frac{\partial T}{\partial \dot{\theta}}-\frac{\partial T}{\partial \theta}=Q_{\theta} \\
& \frac{d}{d t} \frac{\partial T}{\partial \dot{x}}-\frac{\partial T}{\partial x}=Q_{x}
\end{aligned}
$$

де $T$ - кінетична енергія елементів регулятора; $Q_{\theta}$ $i Q_{x}$ - узагальнені сили, що є коефіцієнтами, які стоять у виразі суми робіт силами, що задаються при відповідних узагальнених можливих переміщеннях; $\partial \dot{\theta}$ та $\partial \dot{x}-$ узагальнені швидкості.

Силами системи, що задаються $\epsilon: P$ - вага кожного 3 тягарців; пара сил 3 обертальним моментом $m_{0}$, а також сила пружності пружини стискання, яка в цьому разі направлена горизонтально. Сила пружності визначається як:

$$
F_{n p}=F_{n p_{0}}+c\left(x-x_{0}\right)
$$

де $x_{0}-$ початкове стискання пружини, що відповідає номінальній кутовій швидкості ротора; $F_{n p_{0}}-$ початковий натяг пружини, що відповідає номінальній кутовій швидкості ротора; $x$ зміщення тягарця від осі обертання, що відповідає поточній кутовій швидкості ротора; $c$ жорсткість пружини.
Знайдемо узагальнені сили. Для цього надамо регулятору можливий кут повороту вала $\delta \theta$, вважаючи при цьому можливе переміщення тягарців $\delta x=0$.

Вирахуємо суму робіт активних сил на узагальненому можливому переміщенні $\delta \theta$ :

$$
\delta A=m_{0} \delta \theta .
$$

Враховуючи, що $\delta A=Q_{\theta} \delta \theta$, отримаємо $Q_{\theta}=m_{0}[2]$.

Робота сили $F_{n p}=0$, тому, що вважаємо $\delta x=0$ і робота сили $P=0$.

Надамо тягарцям регулятора можливе переміщення $\delta x$, вважаючи $\delta \theta=0$, тоді:

$$
\delta A=-F_{n p} \delta x
$$

і тоді, відповідно, $Q_{x}=-F_{n p}$.

Вирахуємо кінетичну енергію елементів регулятора:

$$
T=T_{t} n+T_{m},
$$

де $T_{t}$ - енергія одного тягарця; $T_{m}-$ енергія ротора, маточини і напрямних; $n$ - кількість тягарців.

$T_{t}$ знаходиться з виразу: 


$$
T_{t}=\frac{1}{2} \frac{P}{g} \vartheta_{A M}^{2},
$$

де $\vartheta_{\text {Ам }}$ - модуль абсолютної швидкості тягарця; $g$ - прискорення вільного падіння.

Кожен тягарець бере участь у складному русі: переносному обертальному навколо вертикальної осі і відносному поступальному вздовж напрямних, тоді:

$$
\vec{\vartheta}_{A M}=\vec{\vartheta}_{e M}+\vec{\vartheta}_{r M}
$$

де $\vartheta_{e M}=|O M| \omega=x \dot{\theta}-\quad$ переносна обертальна лінійна швидкість на радіусі $x=|\mathrm{OM}| ; \omega-$ кутова швидкість обертання ротора; $\vartheta_{r M}=\dot{x}-$ відносна поступальна швидкість тягарця вздовж напрямної.

Зважаючи на те, що швидкості $\vec{\vartheta}_{e M}$ і $\vec{\vartheta}_{r M}$ взаємоперпендикулярні, то квадрат модуля швидкості в абсолютному русі складе:

$$
\vartheta_{A M}^{2}=x^{2} \dot{\theta}^{2}+\dot{x}^{2} .
$$

Енергія ротора, маточини і напрямних $T_{m}$ складе:

$$
T_{m}=\frac{1}{2} J_{p} \dot{\theta}^{2},
$$

де $J_{p}$ - момент інерції ротора (який включає моменти інерції маточини, лопатей, самого регулятора та інших пов'язаних з ротором складових).

Тоді в загальному результаті маємо:

$$
\begin{aligned}
T & =\frac{1}{2} \frac{P}{g} \vartheta_{A M}^{2} n+\frac{1}{2} J_{p} \dot{\theta}^{2}=\frac{1}{2} \frac{P}{g} x^{2} \dot{\theta}^{2} n+\frac{1}{2} \frac{P}{g} \dot{x}^{2} n+ \\
& +\frac{1}{2} J_{p} \dot{\theta}^{2}=\frac{n}{2}\left(\frac{P}{g} x^{2}+J_{p}\right) \dot{\theta}^{2}+\frac{1}{2} \frac{P}{g} \dot{x}^{2} n
\end{aligned} .
$$

Знайдемо складові рівнянь Лагранжа:

$$
\frac{\partial T}{\partial \dot{\theta}}=n\left(\frac{P}{g} x^{2}+J_{p}\right) \dot{\theta} ; \frac{\partial T}{\partial \dot{x}}=n \frac{P}{g} \dot{x} ;
$$

$$
\begin{gathered}
\frac{d}{d t} \frac{\partial T}{\partial \dot{\theta}}=n\left(\frac{P}{g} x^{2}+J_{p}\right) \ddot{\theta}+2 n \frac{P}{g} x \dot{x} \dot{\theta} ; \frac{d}{d t} \frac{\partial T}{\partial \dot{x}}=n \frac{P}{g} \ddot{x} ; \\
\frac{\partial T}{\partial \theta}=0 ; \frac{\partial T}{\partial x}=n \frac{P}{g} \dot{\theta}^{2} x .
\end{gathered}
$$

Підставимо їх у вираз (1) і тоді отримаємо:

$$
\begin{aligned}
& n\left(\frac{P}{g} x^{2}+J_{p}\right) \ddot{\theta}+2 n \frac{P}{g} x \dot{x} \dot{\theta}=m_{0} ; \\
& n \frac{P}{g} \ddot{x}-n \frac{P}{g} \dot{\theta}^{2} x=-\left(F_{n p_{0}}+c\left(x-x_{0}\right)\right) .
\end{aligned}
$$

В усталеному режимі регулятора $m_{0}=0$; та $\dot{\theta}=\omega=$ const $; x=$ const $; \dot{x}=0$, тоді:

$$
-n \frac{P}{g} \omega^{2} x=-\left(F_{n p_{0}}+c\left(x-x_{0}\right)\right),
$$

звідки кутова швидкість обертання ротора складе:

$$
\omega=\sqrt{\frac{F_{n p_{0}}+c\left(x-x_{0}\right)}{m n x},}
$$

де $m=\frac{P}{g}-$ маса тягарця.

Вираз (6) є статичною характеристикою даного відцентрового регулятора в координатах $\omega=f(x)$.

Запишемо вираз для $F_{n p_{0}}$. При $x=x_{0}$ кутова швидкість відповідає номінальній кутовій швидкості $\omega_{H}$. Тоді:

$$
F_{n p_{0}}=m n \omega_{H}^{2} x_{0} .
$$

Вираз (7) дозволяє визначити параметри регулятора при його налагоджуванні на номінальні оберти. В разі, якщо це маса тягарців, будемо мати:

$$
m=\frac{F_{n p_{0}}}{n \omega_{H}^{2} x_{0}} .
$$

В разі вибору початкового стискання пружини її величина складе:

$$
x_{0}=\frac{F_{n p_{0}}}{m n \omega_{H}^{2}} .
$$


3 урахуванням виразу (7) вираз для статичної характеристики регулятора набуде вигляду:

$$
\omega=\sqrt{\frac{m n \omega_{H}^{2} x_{0}+c\left(x-x_{0}\right)}{m n x}} .
$$

До тягарця $\boldsymbol{M}$ може бути прикріплений гнучкий зв'язок, що кінематично з'єднаний 3 механізмом повороту лопаті. Тоді $x$ та $x_{0}$ можна виразити як:

$$
\begin{gathered}
x=2 \pi R \varphi, \\
x_{0}=2 \pi R \varphi_{0},
\end{gathered}
$$

де $\varphi$ - кут розвороту лопаті; $\varphi_{0}-$ початковий кут установки лопаті, що відповідає $x_{0} ; R$-радіус барабану механізму повороту лопаті.

Вираз для статичної характеристики регулятора в координатах $\omega=f(\varphi)$ набуде вигляду:

$$
\omega=\sqrt{\frac{m n \omega_{H}^{2} \varphi_{0}+c\left(\varphi-\varphi_{0}\right)}{m n x}},
$$

що дозволяє отримати статичну характеристику ротора вітроустановки згідно з [6].

Розглянемо конструкцію регулятора (рис. 2 та рис. 3), що описаний у роботі [1]. Відцентрові тягарці 1 з'єднані між собою тросом 2 через обойму 3 роликами 3. Трос 6 охоплює один 3 роликів обойми 3 і одним кінцем з'єднаний 3 валом 5, а іншим - 3 пальцем 4, що кріпиться до повзуна 7, який переміщується вздовж вала 5 та взаємодіє з пружиною 8. Зміна кута встановлення лопаті здійснюється за рахунок відцентрових тягарців, що переміщуються під дією відцентрових сил, які виникають при обертанні ротора, і далі з допомогою лучкового механізму 9 розвертають лопаті 10.

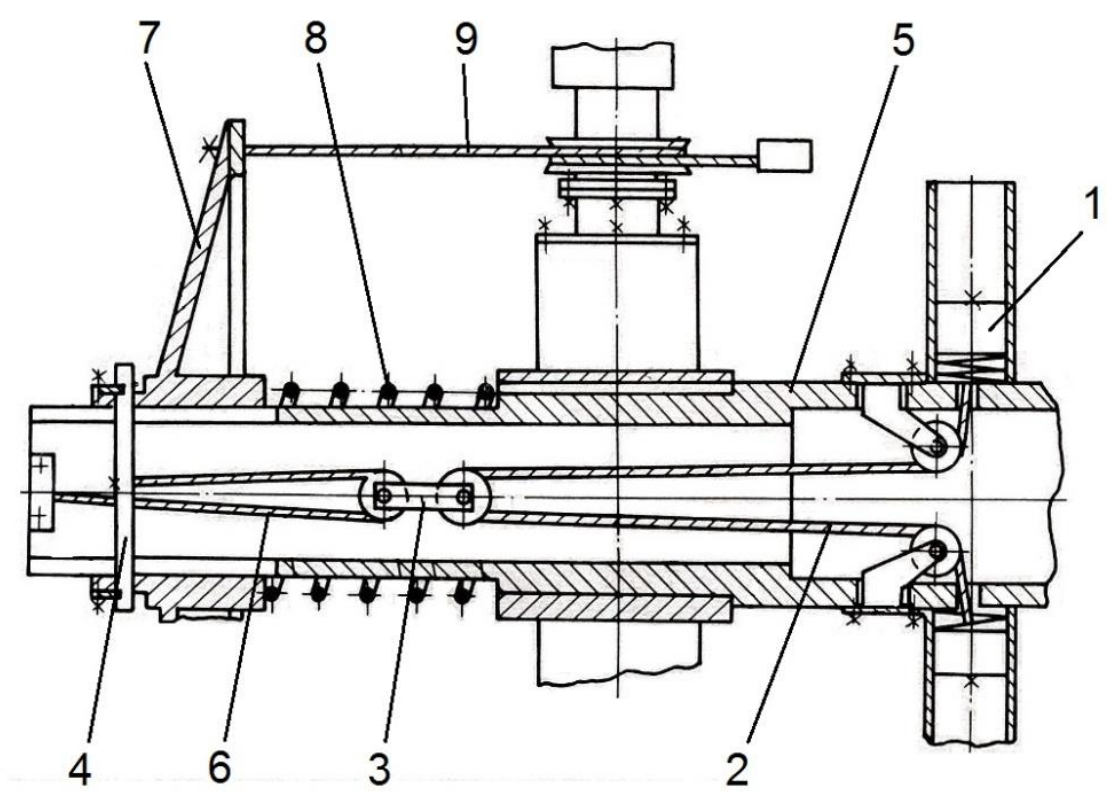

Рис. 2. Загальний вигляд відцентрового регулятора

Fig. 2. General view of the centrifugal regulator 


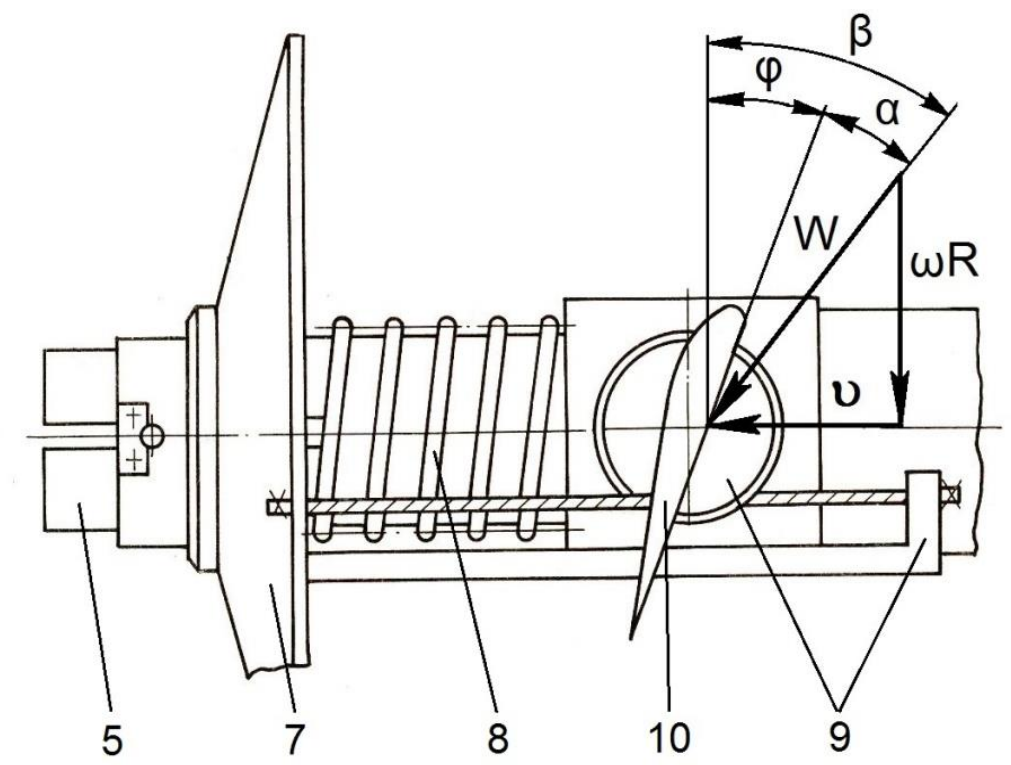

Рис. 3. Вид регулятора зверху та план швидкостей на елементі лопаті

Fig. 3. Top view of the regulator and speed plan on the blade element

На рис. 4 наведена принципова схема даного відцентрового регулятора.

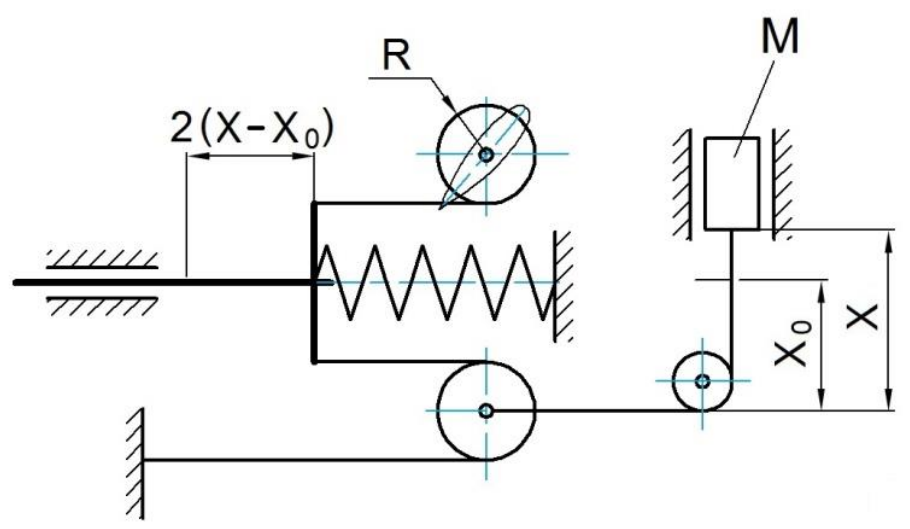

Рис. 4. Принципова схема відцентрового регулятора

Fig. 4. Schematic diagram of a centrifugal regulator

Як видно 3 рис. 4, зміщення повзуна на величину $\left(x-x_{0}\right)$ трансформується у стискання пружини на величину $2\left(x-x_{0}\right)$ i, відповідно, рівняння (5) запишемо як:

$$
-n m \omega^{2} x=-2\left(F_{n p_{0}}+2 c\left(x-x_{0}\right)\right) .
$$

Тоді вираз для $F_{n p_{0}}$ набуде вигляду:

$$
F_{n p_{0}}=\frac{1}{2} m n \omega_{H}^{2} x_{0},
$$

а вирази (8) та (9), що дозволяють визначити параметри даного регулятора при його налагоджуванні на номінальні оберти, відповідно, будуть:

$$
\begin{aligned}
& m=\frac{2 F_{n p_{0}}}{n \omega_{H}^{2} x_{0}}, \\
& x_{0}=\frac{2 F_{n p_{0}}}{m n \omega_{H}^{2}} .
\end{aligned}
$$


3 урахуванням виразу (15) вираз для статичної характеристики запишемо як:

$$
\omega=\sqrt{\frac{m n \omega_{H}^{2} x_{0}+4 c\left(x-x_{0}\right)}{m n x}} .
$$

Якщо за координату $x$ прийняти переміщення пружини, то рівняння (5) набуде вигляду:

$$
-\frac{1}{2} n m \omega^{2} x=-F_{n p_{0}}+c\left(x-x_{0}\right),
$$

та, відповідно, вираз для статичної характеристики буде:

$$
\omega=\sqrt{\frac{m n \omega_{H}^{2} x_{0}+2 c\left(x-x_{0}\right)}{m n x}},
$$

і 3 урахуванням виразів (11), (12) вираз для статичної характеристики в координатах $\omega=f(\varphi)$ запишемо в такому вигляді:

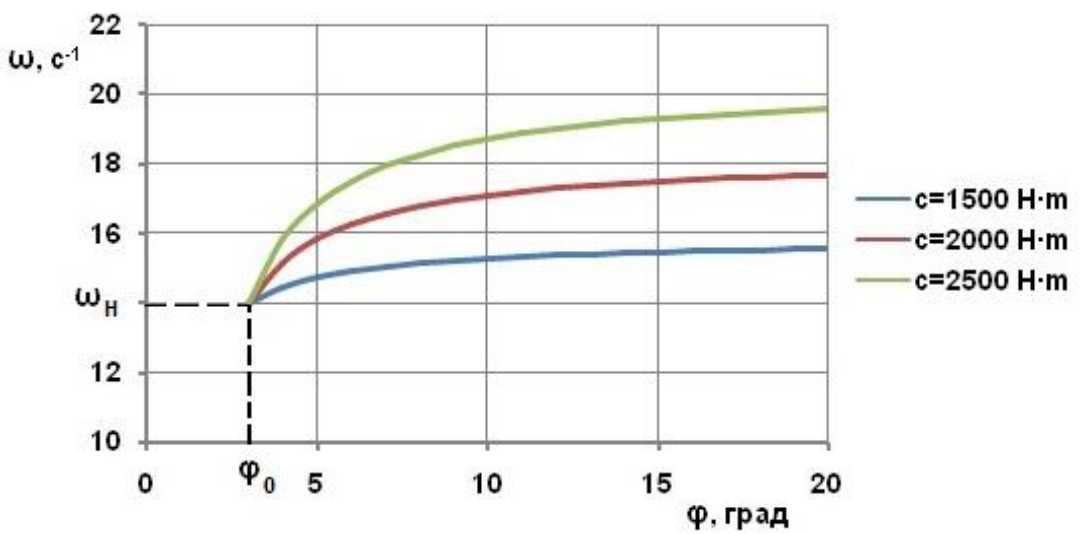

Рис. 5. Статичні характеристики відцентрового регулятора

Fig. 5. Static characteristics of the centrifugal regulator

Статичні характеристики, що наведені на рис. 5, дозволяють вибрати жорсткість пружини для забезпечення необхідного діапазону відхилень обертів ротора від номінального значення в заданому діапазоні кутів регулювання.

Для пояснення принципу регулювання поворотом лопаті розглянемо наведену в $[7,8]$ залежність коефіцієнта підйомної сили у функції від кута атаки $\alpha$. Слід врахувати, що кут атаки та

$$
\omega=\sqrt{\frac{m n \omega_{H}^{2} \varphi_{0}+2 c\left(\varphi-\varphi_{0}\right)}{m n x}},
$$

Для прикладу розглянемо статичні характеристики регулятора при різних значеннях жорсткості пружини (рис. 5). Для даних статичних характеристик було прийнято: $F_{n p_{0}}=123 \mathrm{H}$; $x_{0}=0,3 \mathrm{м} ; \quad R=0,05 \mathrm{м} ; \quad n=3 ; \quad m=4$ кг; $\quad \omega_{H}=14 \mathrm{c}^{-1}$; $\varphi_{0}=3^{\circ}$. При цьому початковий кут встановлення $\varphi_{0}$ визначається при аеродинамічному розрахунку параметрів ротора, але в даній конструкції є можливість його змінювати. Для цього потрібно розфіксувати лучковий механізм відносно маха лопаті та виставити початковий кут, а потім зафіксувати. 
тангенційної швидкості $\omega r$, що обумовлена обертанням ротора 3 кутовою швидкістю $\omega .3$ рис. 3 видно, що при постійних обертах ротора (тобто кут $\beta$ постійний) зменшення кута встановлення $\varphi$ приводить до збільшення кута атаки $\alpha$. Кут атаки збільшується майже лінійно до певної величини (до критичного значення), що для більшості профілів складає приблизно $12^{\circ} \ldots 14^{\circ}$. Подальше його збільшення призводить до різкого зменшення коефіцієнта підйомної сили $C_{y}$.

Висновки. 1. Запропоновано методику розрахунку відцентрового регулятора для вітроустановок з використання рівнянь Лагранжа другого роду.

2. Отримано вираз для статичної характеристики даного регулятора, що дає змогу вибрати жорсткість пружини для забезпечення необхідного діапазону відхилень обертів ротора від номінального значення в заданому діапазоні кутів регулювання.

1. Шихайлов Н.А., Шевченко Ю.В., Коваленко В.И. Регулятор частоты вращения ветроколеса. А. с. СССР №1038541. Опубл. 30.08.1983 г., бюл. № 32.

2. Бать М.И., Джанелидзе Г.Ю., Кельзон А.С. Теоретическая механика в примерах и задачах. М. Гос. издво физико-математических наук. 1961. 616 с.

3. Цукерник Л.М. Теория и расчет центробежного регулятора. М. Машгиз. $1951.110 \mathrm{c}$.

4. Сабинин Г.Х. Теория регулирования быстроходных ветродвигателей поворотом лопастей центробежным регулятором. Промышленная аэродинамика. 1957. Сб. № 8. C. 5-77.

5. Сабинин Г.Х. Теория регулирования быстроходных ветряков центробежным регулятором с помощью поворота лопастей. Вопросы энергетики. 1959. С. 37-49.

6. Коханєвич В.П. Статика регулювання роторів вітродвигунів відцентровими регуляторами при антифлюгерному регулюванні. Відновлювана енергетика. 2009. № 3(18). C. 18-24.

7. Мхитарян А.М., Ушаков В.В., Баскакова А.Г. и др. Аэрогидромеханика. Под ред. проф. А.М. Мхитаряна. М. Машиностроение. 1984. 352 с.

8. Фатеев Е.M. Ветродвигатели и ветроустановки. М. Госсельхозиздат. 1957. 536 с.

\section{REFERENCES}

1. Shykhaylov N.A., Shevchenko YU.V., Kovalenko V.I. Regulyator chastoty vrashcheniya vetrokolesa. [Wind wheel speed regulator]. A. s. USSR №1038541. Opubl. 30.08.1983 g., byul. No. 32. [in Russian].

2. Bat M.I., Dzhanelidze G.Yu., Kelzon A.S. Teoreticheskaya mekhanika $\mathrm{v}$ primerakh i zadachakh. [Theoretical mechanics in examples and problems]. M. Gos. izdvo fiziko-matematicheskikh nauk. 1961. 616 p. [in Russian].

3. Tsukernyk L.M. Teoriya i raschet tsentrobezhnogo regulyatora. [Theory and calculation of a centrifugal regulator]. Moskow. Mashgiz. 1951. 110 p. [in Russian].

4. Sabinin G.H. Teoriya regulirovaniya bystrokhodnykh vetrodvigateley povorotom lopastey tsentrobezhnym regulyatorom. [Theory of regulation of high-speed wind turbines by turning blades by a centrifugal regulator]. Industrial aerodynamics. 1957. Sb. No. 8. Pp. 5-77. [in Russian].

5. Sabinin G.H. Teoriya regulirovaniya bystrokhodnykh vetryakov tsentrobezhnym regulyatorom s pomoshch'yu povorota lopastey. [The theory of regulation of high-speed windmills by a centrifugal regulator by means of rotation of blades]. Energy issues. 1959. Pp. 37-49. [in Russian].

6. Kokhanyevich V.P. Statyka rehulyuvannya rotoriv vitrodvyhuniv vidtsentrovymy rehulyatoramy pry antyflyuhernomu rehulyuvanni. [Static characteristics of the centrifugal regulator at weather vane regulation of the rotor of the wind turbine]. Vidnovlyuvana enerhetika. 2009. No. 3(18). Pp. 18-24. [in Ukrainian].

7. Mkhitaryan A.M., Ushakov V.V., Baskakova A.G. $i d r$. Aerogidromekhanika. [Aerogidromekhanika]. Pod red. prof. A.M. Mkhitaryana. Moskow. Mashinostroyeniye. 1984. 352 p. [in Russian].

8. Fateyev Ye.M. Vetrodvigateli i vetroustanovki. [Vetrodvigateli i vetroustanovki]. Moskow. Gosselkhozizdat. 1957. 536 p. [in Russian].

Стаття надійшла до редакції 26.04.21 Остаточна версія 01.12.21 